\title{
COMPARISON OF MISOPROSTOL WITH OXYTOCIN IN THIRD STAGE OF LABOUR
}

\author{
Nilam Subedi ${ }^{1}$, Deepanjali Sharma ${ }^{1}$, Rubby $\operatorname{Das}^{2}$
}

\begin{abstract}
INTRODUCTION

Postpartum Haemorrhage (PPH) is one of the leading cause of maternal mortality worldwide. A simple measure to prevent $\mathrm{PPH}$ is active management of third stage of labour (AMTSL). This prospective study was conducted in Universal College of Medical Sciences and Teaching Hospital, Tribhuvan University, Bhairahawa where misoprostol 600 mcg orally was compared with the standard oxytocin regime in active management of third stage of labour.
\end{abstract}

\section{MATERIAL AND METHODS}

A total of 100 women were selected to receive either $600 \mathrm{mcg}$ misoprostol orally or 10 IU oxytocin intramuscularly. The incidences of postpartum hemorrhage and side effects were examined.

\section{RESULTS}

Both groups were comparable in age, parity, gestational age, pre-delivery hemoglobin, and duration of labor. There was no significant differences between the misoprostol and oxytocin groups in terms of blood loss ( $96 \% \mathrm{vs} 100 \%$ had blood loss of $<500 \mathrm{ml}, \mathrm{p}=0.475)$. and incidence of PPH (4\% vs 0\%). None of the group had severe PPH i.e. blood loss $>1000 \mathrm{ml}$. The duration of the third stage of labor, a secondary outcome measure was shorter in the misoprostol group than in the oxytocin group (7.02 $\pm 2.26 \mathrm{SD}$ vs $8.44 \pm 4.08 \mathrm{SD}, \mathrm{p}=0.034)$. Two women of oxytocin group received a blood transfusion. The adverse effects of shivering and pyrexia were encountered more frequently in the misoprostol than in the oxytocin group ( $(2 \%$ vs $38 \%, \mathrm{p}<0.001, \mathrm{P}<0.001$; and $2 \%$ vs $10 \%, \mathrm{p}=0.207)$. No major surgical intervention for atonic $\mathrm{PPH}$ was needed and no maternal deaths occurred in either group.

\section{CONCLUSION}

Misoprostol $600 \mathrm{mcg}$ orally is equally as effective as standard oxytocin regime in AMTSL to prevent PPH and can be safely used in the peripheral institutions or by midwives where there is lack of trained personnel and storage facility.

KEY WORDS Third Stage of Labour, Postpartum Haemorrhage, Misoprostol, Oxytocin,

1. Lecturer, Department of Obstetrics \& Gynaecology, Universal College of Medical Sciences, Bhairahawa, Nepal

2. Resident, Department of Obstetrics \& Gynaecology, Universal College of Medical Sciences, Bhairahawa, Nepal

For Correspondence

Dr. Nilam Subedi

Lecturer

Department of Obstetrics \& Gynaecology

Universal College of Medical Sciences

Bhairahawa, Nepal

Email:nsnilam16@gmail.com 


\section{INTRODUCTION}

Postpartum hemorrhage (PPH) is the leading cause of maternal death worldwide with an estimated mortality rate of 140,000 per year or one maternal death every four minutes. ${ }^{1} \quad$ Maternal mortality rate in Nepal is high i.e. 281/ 100,000 live births and almost half of which is a result of PPH. ${ }^{2}$ Injection of an uterotonic drug immediately after delivery of newborn is one of the most important intervention used to prevent PPH and the most commonly used uterotonic drug is oxytocin. $^{3}$ Giving oxytocin in rural areas has many problems, like lack of refrigeration for storage facility, shortage of skilled hand to administer them and non availability of sterile syringes and needles. Therefore, there is need for a safe, effective, affordable, thermostable and non parenteral uterotonic drug. Misoprostol, a prostaglandin E1 analogue, has potent uterotonic action, is cheap, does not require refrigeration and has few side effects. It can be given orally, sublingually, vaginally and rectally. ${ }^{4}$

The aim of this study was therefore to evaluate the effectiveness of misoprostol $600 \mu \mathrm{gm}$ orally in comparison to that of 10 units of oxytocin by intramuscular regime in active management of third stage of labour (AMTSL) for prevention of PPH in low risk vaginal deliveries.

\section{MATERIAL AND METHODS}

Prospective randomized study was conducted among 100 women undergoing spontaneous vaginal deliveries at UCMSTH from June 2017 to November 2017. Women admitted in labour room with spontaneous labour were screened for inclusion in study by history and clinical examination.

Inclusion criteria:- Age group (16-40 years), GA (37-42 weeks), vertex presentation, parity (0-4), spontaneous vaginal delivery of a single live neonate and absence of contraindication for use of Misoprostol.

Exclusion criteria:- Women were excluded from study if they had known risk factors of PPH like grand multiparity $>5$, polyhydramnios, foetal macrosomia, APH, prolonged labour, or $\mathrm{h} / \mathrm{o} \mathrm{PPH}$ in previous pregnancies, post dated pregnancy. Women with anaemia, cardiovascular, respiratory, liver or haematological disease were also excluded. Study was approved by institutional review committee (IRC). Written informed consent was obtained during $1^{\text {st }}$ stage of labour. Women fulfilling the inclusion criteria were admitted in the labor room and were screened for the study by interview and clinical examination. Pre-delivery hemoglobin level along with routine screening laboratory tests were carried out. Labor was monitored by partograph. When delivery was imminent, the participant was asked to randomly pick a numbered sealed pack from the box. The number in the envelope was entered in computer. The envelope contained either 3 tablets of misoprostol and 2 ampoules containing placebo ( $2 \mathrm{ml}$ of distilled water) or 3 tablets placebo and 2 ampoules of oxytocin (10 IU). Immediately after delivery of baby 3 tablets were given orally and contents of ampoules was given intramuscularly. Cord was clamped immediately and amniotic fluid if any was allowed to drain. Placenta was delivered by controlled cord traction and duration of third stage was noted. Pre-weighed cotton pads were placed under the buttock after second stage of labor to measure quantity of blood loss during third stage of labor. The cotton pads under the buttock were replaced during the 1hour observation period. One hour after delivery, the bloodsoaked cotton pads and the blood clots in the bag were weighed. The previous weight of same dry pads was subtracted from weight of blood soaked pads to assess blood loss. The specific gravity of blood being 1.08 , the amount of blood lost in milliliters was approximately equal to the weight in grams. Episiotomy wound (if present) was repaired immediately and the swabs for it were excluded from blood loss assessment.

Excessive blood loss due to uterine atonicity in two patients on misoprostol needed oxytocin, two on oxytocin needed carboprost and one needed methergine as an additional uterotonic drug, as per standard protocol of the hospital. Patient was observed for any blood loss or development of toxicity of drug used or occurrence of PPH for 24 hours. After $24 \mathrm{hrs}$ of delivery, hemoglobin level was measured again.

\section{RESULTS}

Both groups were comparable in age, parity, gestational age, estimated blood loss requirement of additional oxytocin drug, blood transfusion, toxicity, duration of labor, duration of $3^{\text {rd }}$ stage of labor and change in hemoglobin.There was no significant difference in age distribution ( $24+/-4.49 \mathrm{SD}$ and $23.3+/-3.57 \mathrm{SD}, \mathrm{p}=0.23)$, gravida $(2+/-1.32 \mathrm{SD}$ and $1.78+/-$ $1.06 \mathrm{SD}, \mathrm{p}=0.361)$ and gestational age $(38.62+/-1.03 \mathrm{SD}$ and $38.34+/-1.00 \mathrm{SD}, \mathrm{p}=0.171)$ in both groups (table 1$)$.

Table 1. Demographic and Obstetric character

\begin{tabular}{|l|l|l|l|} 
CHARACTER & $\begin{array}{c}\text { OXYTOCIN } \\
\text { (MEAN) }\end{array}$ & $\begin{array}{c}\text { MISOPROSTOL } \\
\text { (MEAN) }\end{array}$ & P VALUE \\
\hline Age (in years) & $24.28 \pm 4.49$ & $23.3 \pm 3.57$ & 0.23 \\
\hline Gravida & $2 \pm 1.32$ & $1.78 \pm 1.06$ & 0.361 \\
\hline GA (in weeks) & $38.62 \pm 1.03$ & $38.34 \pm 1.00$ & 0.171 \\
\hline Pre delivery Hb (gm/dl) & $11.98 \pm 1.89$ & $11.47 \pm 1.71$ & 0.158 \\
\hline Duration of labour (in hours) & $10.48 \pm 2.73$ & $11.36 \pm 4.03$ & 0.205 \\
\hline
\end{tabular}


Table 2. Comparison of oxytocin and misoprostol with (a) various parameters; (b) other uterotonics

\begin{tabular}{|c|c|c|c|}
\hline Parameter & Oxytocin & Misoprostol & $P$ value \\
\hline \multicolumn{4}{|l|}{ Blood loss } \\
\hline$<500 \mathrm{ml}$ & 48 & 50 & \multirow{2}{*}{0.475} \\
\hline$>500 \mathrm{ml}$ & 2 & 0 & \\
\hline Duration of $3^{\text {rd }}$ stage & $8.44 \pm 4.08$ & $7.02 \pm 2.26$ & 0.034 \\
\hline Post delivery $\mathrm{Hb}$ & $11.14 \pm 1.54$ & $10.93 \pm 1.87$ & 0.526 \\
\hline Change in $\mathrm{Hb}$ & $0.85 \pm 1.35$ & $0.57 \pm 1.55$ & 0.328 \\
\hline Blood transfusion & 2 & 0 & 0.475 \\
\hline \multicolumn{4}{|l|}{ Toxicity } \\
\hline Shivering & 1 & 19 & $<0.001$ \\
\hline Pyrexia & 1 & 5 & 0.207 \\
\hline
\end{tabular}

\begin{tabular}{|l|c|c|c|}
\hline Use of other uterotonics & Oxytocin & Misoprostol & P Value \\
\hline Oxytocin (additional) & 0 & 2 & 0.475 \\
\hline Methergin & 1 & 0 & 1 \\
\hline Carboprost & 2 & 0 & 0.475 \\
\hline
\end{tabular}

The only secondary outcome which was statistically significant was shivering, more in misoprostol group than in oxytocin group (19 and 1 respectively, $\mathrm{p}=<0.001$ ). Other secondary outcomes such as duration of third stage, estimated blood loss, post delivery $\mathrm{Hb}$ and change in the blood transfusion, pyrexia and use of other uterotonics were statistically insignificant (Table 2a and b). No major surgical intervention for atonic PPH was needed and no maternal deaths occurred in either group.

\section{DISCUSSION}

PPH is the most common cause of maternal morbidity and mortality and it still remains a challenge to treating obstetrician. There was no incidence of PPH with use of misoprostol in this study. Kundodyiwa ${ }^{5}$ et al found $15.2 \%$ incidence of $\mathrm{PPH}$ with misoprostol. No statistically significant difference was found in duration of $3^{\text {rd }}$ stage of labour in both groups. Similar findings were obtained in studies done by Chaudhuri ${ }^{6}$ et al \& Vimala $^{7}$ et al. There was no significant difference in terms of mean reduction of post delivery $\mathrm{Hb}$, requirement of additional oxytocic drugs or requirement of blood transfusion among both groups in present study. Nearly similar results were observed by Chaudhuri, ${ }^{6}$ Vimala $^{7} \&$ Kundodyiwa ${ }^{5}$ et al. In the present study shivering was significantly higher with oral Misoprostol which was similar with study done by Kundodyiwa, ${ }^{5}$ Singhal ${ }^{8}$ and Chaudhuri ${ }^{6}$ et al. Limitations of present study were small sample size and non inclusion of high risk pregnancies.

In summary, the present study demonstrates that $600 \mu \mathrm{gm}$ oral misoprostol was a safe \& effective alternative to 10 units of IM Oxytocin in routine AMTSL. Hence, misoprostol can be safely used in low risk vaginal deliveries as an alternative to standard oxytocin regimen in AMTSL.

\section{CONCLUSION}

In conclusion, the effectiveness of oral $600 \mathrm{mcg}$ misoprostol was comparable to the standard oxytocin regimen, in terms of occurrence of postpartum hemorrhage in acceptable duration of third stage of labor, blood loss, and requirement of additional uterotonics and postpartum drop in hemoglobin. However, misoprostol was associated with higher incidence of shivering and pyrexia but no other serious adverse effects occurred. Hence, oral misoprostol can be safely used in low risk vaginal deliveries as an alternative to 10 IU oxytocin in AMTSL.

\section{REFERENCES}

1. AbouZahr C. Global burden of maternal death and disability. $\mathrm{Br}$ Med Bull 2003;67:111

2. Demographic Health Survey of Nepal 2006

3. FIGO. Prevention and treatment of postpartum hemorrhage in low-resource settings. Intl J Gynecol Obstet 2012; 117:10818.

4. Chong YS, Chua S, El-Refaey H, Choo WL, Chanrachakul B, Tai $\mathrm{BC}$, et al. Post partum intrauterine pressure studies of the uterotonic effect of oral misoprostol and intramuscular syntometrine . Br J Obstet Gynaecol 2001;108;41-7

5. Kundodyiwa TW, Majoko F, Rusakaniko S. Misoprostol versus oxytocin in the third stage of labor. Int J Gynecol Obstet 2001; 75 :235-41.

6. Chaudhuri P, Biswas J, Mandal A, et al. Sublingual misoprostol versus intramuscular oxytocin for prevention of postpartum hemorrhage in low-risk women. Int J of Gynecology and Obstetrics 2012;116: 138-142

7. Vimala N, Mittal S, Kumar S. Sublingual misoprostol versus oxytocin infusion to reduce blood loss at cesarean section. Int J Gynecol Obstet 2006; 92:106-110. 